\title{
Fungi and Mycotoxins in Feed Intended for Sows at Different Reproductive Stages in Argentina
}

\author{
Carina Maricel Pereyra,, ${ }^{1,2}$ Lilia Renée Cavaglieri, ${ }^{1,2}$ Stella Maris Chiacchiera, ${ }^{2,3}$ \\ and Ana María Dalcero ${ }^{1,2}$ \\ ${ }^{1}$ Departamento de Microbiología e Inmunología, Universidad Nacional de Río Cuarto, CONICET, Ruta 36, km 601, Río Cuarto, \\ 5800 Córdoba, Argentina \\ ${ }^{2}$ Consejo Nacional de Investigaciones Científicas y Tecnológicas (CIC-CONICET), Carrera del Investigador Científico, Rivadavia 1917, \\ CP C1033AAJ, Buenos Aires, Argentina \\ ${ }^{3}$ Departamento de Química, Universidad Nacional de Río Cuarto, Ruta 36, km 601, Río Cuarto, 5800 Córdoba, Argentina
}

Correspondence should be addressed to Lilia Renée Cavaglieri, lcavaglieri@arnet.com.ar

Received 20 November 2009; Revised 25 February 2010; Accepted 5 April 2010

Academic Editor: Sagar M. Goyal

Copyright () 2010 Carina Maricel Pereyra et al. This is an open access article distributed under the Creative Commons Attribution License, which permits unrestricted use, distribution, and reproduction in any medium, provided the original work is properly cited.

\begin{abstract}
The aim of this study was to evaluate fungi and contamination levels of aflatoxin $\mathrm{B}_{1}$, ochratoxin $\mathrm{A}$, fumonisin $\mathrm{B}_{1}$, and zearalenone in raw materials and finished feed intended for sows at different reproductive stages. Total fungi, Aspergillus, Penicillium, and Fusarium species occurrence, were examined. Aspergillus flavus, A. niger aggregate spp., and F. verticillioides were the prevalent species. Fungal counts exceeded the levels proposed as feed hygienic quality limits $\left(1 \times 10^{4}\right.$ colony forming units $)$ at all reproductive stages. Aflatoxin $\mathrm{B}_{1}$, ochratoxin $\mathrm{A}$, fumonisin $\mathrm{B}_{1}$, and zearalenone were detected by high-pressure liquid chromatography. Aflatoxin levels in $80 \%$ samples of finished sow feeds were over the permitted levels of $0.02 \mu \mathrm{g} \mathrm{g}^{-1}$ (mean $228.2 \pm 95 \mu \mathrm{g} \mathrm{Kg}^{-1}$ ). Fumonisin $\mathrm{B}_{1}$ was detected in all tested raw materials at levels that varied from 50.3 to $1137.64 \mu \mathrm{g} \mathrm{Kg}^{-1}$ and finished feed samples at levels that ranged from 99.8 to $512.4 \mu \mathrm{g} \mathrm{Kg}^{-1}$. Aflatoxin $\mathrm{B}_{1}$, zearalenone, and ochratoxin A were not detected in raw materials. All finished feeds were negative for zearalenone contamination whereas all nonpregnant gilt samples were contaminated with low OTA levels (mean $0.259 \pm 0.123$ ). This fact requires periodic monitoring to prevent the occurrence of mycotoxicosis in animal production, to reduce the economic losses, and to minimize hazards to human health.
\end{abstract}

\section{Introduction}

Commercial mixed feeds are a basic element in modern animal production. They contain mixtures of home grown cereals and imported commodities among other ingredients. The use of such ingredients inevitably leads to the contamination of the final mixed feed with fungi [1]. Mycotoxins are fungal secondary metabolites associated with severe toxic effects to vertebrates and produced by important phytopathogenic spoilage fungi including Aspergillus, Penicillium, Fusarium, and Alternaria species [2].

Aflatoxins (AFs) are mycotoxins with high carcinogenic potential, especially in liver tissue, and possess an acute toxicity at high concentrations. Aflatoxins refer to a group of four mycotoxins, aflatoxin $\mathrm{B}_{1}\left(\mathrm{AFB}_{1}\right)$, aflatoxin $\mathrm{B}_{2}\left(\mathrm{AFB}_{2}\right)$, aflatoxin $G_{1}\left(A F G_{1}\right)$, and aflatoxin $G_{2}\left(A F G_{2}\right)$, and are mainly produced by $A$. flavus and A. parasiticus strains [2]. Ochratoxin A (OTA) is one of the most common and dangerous mycotoxins in foods and feeds produced mainly by $A$. ochraceus, A. carbonarius, and A. niger aggregate spp. in tropical regions, and P. verrucosum in temperate areas [3-5]. OTA has a potent toxicity and the nephrotoxic, hepatotoxic, teratogenic, carcinogenic, and immunosuppressive effects have been demonstrated in all mammalian species [6]. Fumonisin $\mathrm{B}_{1}\left(\mathrm{FB}_{1}\right)$, one of the most important mycotoxins is produced by $F$. verticillioides and associated with known outbreaks of porcine pulmonary edema [7]. Zearalenone (ZEA), an estrogenic metabolite mainly produced by $F$. graminearum, is the cause of hyperestrogenism, the estrogenic syndrome in pigs, and has been reported to occur not only in corn but also in other grains and silage in many areas of the world [6]. 
TABle 1: Composition (\%) of feed intended for sows at different reproductive stages.

\begin{tabular}{|c|c|c|c|}
\hline \multirow{2}{*}{ Ingredients } & \multicolumn{3}{|c|}{ Reproduction sows } \\
\hline & Sow & Nonpregnant gilt* & Pregnant gilt ${ }^{\dagger}$ \\
\hline Milled maize & 60 & 56 & 56 \\
\hline $\begin{array}{l}\text { Deactivated } \\
\text { soybean }\end{array}$ & $4-25$ & 30 & 26 \\
\hline Other cereals & $0-10$ & $2-6$ & 10 \\
\hline $\begin{array}{l}\text { Concentrated } \\
\text { (sugar and } \\
\text { vitamins mix) }\end{array}$ & $5-15$ & $2-8$ & $0-8$ \\
\hline
\end{tabular}

* Feed used to increase ovulation from $20 \%$ to $30 \%$.

${ }^{\dagger}$ Feed intended to optimize the productive yields.

Continuous studies regarding the monitoring of these toxins in products to be used as pig feed are being performed in South America [8-10] and other countries [11]. However, no information is available regarding fungi and mycotoxins contamination in sow feed.

The aim of the present study was to determine the mycobiota and $\mathrm{AFB}_{1}, \mathrm{OTA}, \mathrm{FB}_{1}$, and ZEA contamination from raw materials and finished feed intended for sows at different reproductive stages in Argentina.

\section{Materials and Methods}

2.1. Source of Samples and Feed Composition. Samples of sow feed were collected from two farms located in Baradero (latitude: $39^{\circ} 52^{\prime} \mathrm{S}$; longitude: $59^{\circ} 29^{\prime} \mathrm{W}$ ) Buenos Aires province, eastern region of Argentina. Feed was produced and processed on farm and was intended for reproductive sows. Ten samples $(3 \mathrm{~kg})$ of each raw material and finished reproduction sows feed were randomly obtained monthly from the line production and taken to the laboratory, from May to September 2008. Two kinds of raw materials, corn meal, and soybean intended for feed manufacturing, were collected. The composition of the three kinds of finished feed samples is described in Table 1. Primary samples were homogenized, milled, and quartered to get $1 \mathrm{~kg}$ laboratory samples. Mycological evaluation was immediately done. Then, all samples were stored at $-20^{\circ} \mathrm{C}$ up to one week for mycotoxins analyses.

2.2. Mycological Determination. Total fungal counts from samples were performed onto dichloran rose bengal chloranphenicol agar (DRBC), a general media used for estimating total culturable fungi, onto dichloran $18 \%$ glycerol agar (DG18), a media that has low water activity $\left(\mathrm{a}_{W}\right)$ and favours xerophilic fungi development [12]. Quantitative enumeration was done using the surface-spread method. Ten grams of each sample were homogenized in $90 \mathrm{~mL} 0.1 \%$ peptone water solution for 30 minutes in an orbital shaker. Serial dilutions $\left(10^{-2}\right.$ to $\left.10^{-3}\right)$ were made and $0.1 \mathrm{~mL}$ aliquots were inoculated in duplicates onto the culture media. Plates were incubated at $25^{\circ} \mathrm{C}$ for $7-10$ days in darkness. Only plates containing 10-100 colony-forming units (CFUs) were used for counting. The results were expressed as CFU per gram of sample $\left(\mathrm{CFU} \mathrm{g}{ }^{-1}\right)$. Representative colonies of Aspergillus and Penicillium spp. were transferred for subculturing to tubes containing malt extract agar (MEA) and Fusarium spp. were transferred to carnation leaf agar (CLA). Fungal species were identified according to taxonomic keys [12-14]. Results were expressed as isolation frequency (\% of samples in which each genera was present) and relative density (\% of isolation of each species among strains of the same genera).

2.3. Mycotoxins Analyses. Aflatoxin $\mathrm{B}_{1}$, $\mathrm{OTA}, \mathrm{FB}_{1}$, and ZEA were determined in raw materials and finished reproductive sows feed as follows.

2.3.1. Aflatoxin $B_{1}$ Determination. A $50 \mathrm{~g}$ portion of sample was extracted with $150 \mathrm{~mL}$ methanol: water $(80: 20$, v/v) during 60 minutes into a blend jar. The mixture was filtered through filter paper Whatman $\mathrm{N}^{\circ} 4$ (Whatman, Inc., Clifton, New Jersey, USA) and a $2.5 \mathrm{~mL}$ aliquot taken and $2.5 \mathrm{~mL}$ of acetonitrile was added. This mixture was placed into $10 \mathrm{~mL}$ culture tube. Multifunctional columns Mycosep 228 (MFC, Romer Labs, Inc., MO., USA) were used for clean the samples. The extract was forced through frit, through 1 -way valve, and through packing material. Purified extract $(100 \mu \mathrm{L})$ was collected in a column reservoir and diluted with $300 \mu \mathrm{L}$ of the mobile phase.

Aflatoxin $B_{1}$ detection and quantification from each sample was performed by High-Performance Liquid Chromatography (HPLC) according to the methodology proposed by Trucksess et al. [15]. An aliquot $(200 \mu \mathrm{L})$ was derivatized with $700 \mu \mathrm{L}$ trifluoroacetic acid-acetic acid-water $(20: 10: 70$, $\mathrm{v} / \mathrm{v})$. Chromatographic separations were performed on a reversed phase column (Silica Gel, $150 \times 4.6 \mathrm{~mm}$ id., 5$\mu$ particle size, VARIAN, Inc. Palo Alto, USA). Methanolwater $(60: 40 \mathrm{v} / \mathrm{v})$ was used as mobile phase at a flow rate $1 \mathrm{~mL} \mathrm{m^{-1 }}$. Fluorescence of AF derivatives was recorded at excitation and emission wavelengths of $\lambda 360 \mathrm{~nm}$ and $\lambda 460 \mathrm{~nm}$, respectively. Standard curves were constructed with different levels of $\mathrm{AFB}_{1}$. This toxin was quantified by correlating peak heights of sample extracts with those of standard curves. The detection limit of the analytical method was $0.4 \mathrm{ng} \mathrm{g}^{-1}$.

2.3.2. Ochratoxin A Determination. The detection of OTA in samples was performed by HPLC following the methodology proposed by Scudamore and MacDonald [16], with some modifications. Ground samples $(50 \mathrm{~g})$ were extracted with $100 \mathrm{~mL}$ of methanol: water $(80: 20, \mathrm{v} / \mathrm{v})$. The mixture was shaken for 30 minutes and filtered. An aliquot of $10 \mathrm{~mL}$ was mixed with $40 \mathrm{~mL}$ of distilled water and filtered through a microfiber filter (VICAM, Digen Ltd., Exford). Ten $\mathrm{mL}$ of either portion was taken and transferred to an immunoaffinity column (Ochra-Test, Vicam, Digen Ltd. Oxford). The column was washed with $10 \mathrm{~mL}$ PBS containing $0.01 \%$ Tween 20 and then with $10 \mathrm{~mL}$ distilled water. Ochratoxin A was eluted from the column with methanol (HPLC grade), again at a flow rate of 1-2 drops per second. The eluate was evaporated to dryness in a stream of nitrogen. Prior to HPLC 
analysis, samples were redissolved in $200 \mu \mathrm{L}$ of the mobile phase.

The HPLC apparatus used for determination of OTA was a Hewlett Packard chromatograph with a loop of $20 \mathrm{~mL}$, equipped with a spectrofluorescence detector (excitation, $\lambda$ $330 \mathrm{~nm}$; emission, $\lambda 460 \mathrm{~nm}$ ) and a C18 column (Supelcosil LC-ABZ, Supelco; $150 \mathrm{~mm}, 4.6 \mathrm{~mm}, 5 \mathrm{~mm}$ particle size) connected to a precolumn (Supelguard LC-ABZ, Supelco; $20 \mathrm{~mm}, 4.6 \mathrm{~mm}, 5 \mathrm{~mm}$ particle size). The mobile phase was pumped at $1.0 \mathrm{~mL} \mathrm{~min}^{-1}$ and consisted of an isocratic system as follows: $57 \%$ acetonitrile, $41 \%$ water, and $2 \%$ acetic acid. Ochratoxin was quantified on the basis of HPLC fluorometric response compared with OTA standard (Sigma-Aldrich, St. Louis, MO, USA; purity >99\%). The detection limit of the method was $0.1 \mathrm{ng} \mathrm{g}^{-1}$.

2.3.3. Fumonisins Determination. Fumonisins content was determined by high-pressure liquid chromatography (HPLC). Samples $(25 \mathrm{~g})$ were grounded, extracted with $50 \mathrm{~mL}$ of methanol: water $(30: 10, \mathrm{v} / \mathrm{v})$, and shaken 30 minutes in an orbital shaker. The extract was filtered through filter paper Whatman $\mathrm{N}^{\circ} 4$. The extract was quantitatively analysed for $\mathrm{FB}_{1}$ and $\mathrm{FB}_{2}$ by HPLC using the methodology proposed by Shephard et al. [17] and modified by Doko et al. [18]. An aliquot $(50 \mu \mathrm{L})$ of this solution was derivatized with $200 \mu \mathrm{L}$ of $o$-phthaldialdehyde (OPA). The OPA solution was obtained by adding $5 \mathrm{~mL}$ of $0.1 \mathrm{M}$ sodium tetraborate and $50 \mu \mathrm{L}$ of 2 -mercaptoethanol to $1 \mathrm{~mL}$ of methanol containing $40 \mathrm{mg}$ of OPA. Fumonisins OPA derivatives ( $20 \mu \mathrm{L}$ solution) were analysed using a reverse-phase high-pressure liquid chromatography/fluorescence detection system. The HPLC system consisted of a Hewlett Packard 1050 pump (Palo Alto, CA, USA) connected to a Hewlett Packard 3395 integrator. Chromatographic separations were performed on a stainless steel Supelcosil LC-ABZ, C 18 reverse-phase column (150 $\times 4.6 \mathrm{~mm}$ i.d., $5 \mu \mathrm{m}$ particle size; Supelco) methanol/0.1 M sodium dihydrogen phosphate. Fumonisins were quantified by using area measurements and by comparison with a reference standard solution. The standard solution was obtained by dissolving crystalline $\mathrm{FB}_{1}$ and $\mathrm{FB}_{2}$ (Division of Food Science and Technology, Pretoria, South Africa) in acetonitrile: water $(10: 10, \mathrm{v} / \mathrm{v})$, at concentrations of 100 and $50 \mu \mathrm{g} \mathrm{mL} \mathrm{m}^{-1}$, respectively. Detection limit of the method was $1 \mu \mathrm{g} \mathrm{Kg}^{-1}$.

2.3.4. Zearalenone Determination. Zeralenone analyses were performed by thin layer chromatography (TLC), following the methodology described in the Official Methods of Analysis [19]. Each sample (25 g) was extracted with $125 \mathrm{~mL}$ of methanol: water $(60: 40 \mathrm{v} / \mathrm{v}), 80 \mathrm{~mL}$ hexane, and $2 \mathrm{~g} \mathrm{NaCl}$ and shaken 30 minutes in an orbital shaker. The mixture was filtered using filter paper Whatman $\mathrm{N}^{\circ} 4$ (Whatman, Inc., Clifton, New Jersey, USA) and $25 \mathrm{~mL}$ of the filtrated methanol:water phase was extracted twice with 25 and $15 \mathrm{~mL}$ of chloroform, respectively. The chloroform phase was vacuum dried using a rotatory evaporator and the extract was redissolved in $200 \mu \mathrm{L}$ chloroform: acetone $(9: 1 \mathrm{v} / \mathrm{v})$. The extract was screened by spotting $2 \mu \mathrm{L}, 5 \mu \mathrm{L}$, and $10 \mu \mathrm{L}$ of each extract together with standard solution of toxin on a silica gel 60 TLC aluminium sheets $(20 \times 20 \mathrm{~cm}$, Merck, Germany) and developed with chloroform: acetone (90:10 $\mathrm{v} / \mathrm{v})$. Chromatograms were air-dried and observed under 365 and $254 \mathrm{~nm} \mathrm{UV} \mathrm{light.} \mathrm{The} \mathrm{relative} \mathrm{amounts} \mathrm{of} \mathrm{ZEA} \mathrm{were}$ quantitatively determined by visual comparison under UV light with standard solutions of known toxin concentration. A detection limit of the used method was $50 \mu \mathrm{g} \mathrm{kg}^{-1}$.

\section{Results}

Table 2 shows fungal counts from raw materials and finished sows feed from different culture media. Total fungal count analyses from raw materials show that corn obtained the highest values with means ranging from $1.5 \times 10^{4}$ to $2.9 \times$ $10^{5} \mathrm{CFU} \mathrm{g}^{-1}$ and $1 \times 10^{4}$ to $1.5 \times 10^{5} \mathrm{CFU} \mathrm{g}^{-1}$ in $\mathrm{DRBC}$ and DG18, respectively. Soybeans had counts that varied from $<1$ $\times 10^{2}$ to $3 \times 10^{3}$ and $1 \times 10^{2}$ to $1 \times 10^{3} \mathrm{CFU} \mathrm{g}^{-1}$ from DRBC and DG18, respectively. All milled corn samples showed fungal contamination levels over $1 \times 10^{4} \mathrm{CFU} \mathrm{g}^{-1}$, that this is the maximum recommended level [20]. In general, August and September had the highest fungal counts from both DRBC and DG18 media for milled maize.

All finished reproductive sow feed analysed samples had counts higher than $1 \times 10^{4} \mathrm{CFU} \mathrm{g}^{-1}$. Means varied from 3.2 $\times 10^{4}$ to $8.2 \times 10^{4} \mathrm{CFU} \mathrm{g}^{-1}$ in DRBC and from $2.4 \times 10^{4}$ to $1.3 \times 10^{5} \mathrm{CFU} \mathrm{g}^{-1}$ in DG18. September was the period with counts over $1 \times 10^{5} \mathrm{CFU} \mathrm{g}^{-1}$ from both tested media, whereas sow samples were the most contaminated all over the sampling period.

Figure 1 shows the isolation frequency of fungal genera (\%) from raw materials and finished reproduction sows feed. Milled maize and soybean samples contained at least one of the main mycotoxigenic genera. Aspergillus spp., Penicillium spp., Fusarium spp. and yeasts were isolated from all kinds of raw materials at frequencies that varied from $67 \%$ to $75 \%$. Eurotium spp. and Cladosporium spp. contaminated from $75 \%$ to $50 \%$ samples of corn and $33 \%$ to $33 \%$ samples of soybean, respectively. Other fungal species such as Mucorales and Talaromyces spp. were isolated at low frequencies. All finished feed samples (100\%) intended to reproduction sows samples (sow, Nonpregnant gilts, and pregnant gilts) were contaminated by Aspergillus spp., Penicillium spp., and Fusarium spp., Yeasts were isolated from all finished reproduction sows samples at levels that varied from $80 \%$ to $100 \%$, whereas other fungal spp. such as Mucorales, Cladosporium spp., and Talaromyces spp. were present at low levels.

Figure 2 shows the relative density of isolated Aspergillus spp. from raw materials and finished feed. Aspergillus flavus and $A$. niger aggregate spp. were isolated from all raw materials and finished feed. A. flavus was isolated at levels that ranged from $43 \%$ to $54 \%$ and from $35 \%$ to $55 \%$ for raw materials and finished feed, respectively. Aspergillus niger aggregate spp. was isolated from raw materials at levels media from $44.5 \%$ and from finished feed from $40.2 \%$. In soybean and finished feed (sow and pregnant gilt) A. candidus was isolated with a frequency that varied from $10 \%$ to $21 \%$. 
TABLE 2: Fungal counts (CFU/g) from raw materials and finished feed at different reproductive stages in DRBC and DG18 culture media.

\begin{tabular}{lllllll}
\hline $\begin{array}{l}\text { Culture } \\
\text { media }\end{array}$ & $\begin{array}{l}\text { Sampling } \\
\text { period }\end{array}$ & Milled maize & Soybean & Sow & \multicolumn{2}{c}{ Fungal counts (CFU/g)* Media \pm SD } \\
& May & $6.7 \times 10^{4} \pm 4 \times 10^{3}$ & $4.5 \times 10^{2} \pm 8 \times 10^{2}$ & $1 \times 10^{4} \pm 5 \times 10^{3}$ & $2 \times 10^{4} \pm 6 \times 10^{3}$ & $5.9 \times 10^{4} \pm 4 \times 10^{3}$ \\
& June & $9.7 \times 10^{4} \pm 5 \times 10^{3}$ & $<1 \times 10^{2}$ & $2 \times 10^{4} \pm 6 \times 10^{3}$ & $5 \times 10^{4} \pm 7 \times 10^{3}$ & $4 \times 10^{4} \pm 1 \times 10^{4}$ \\
DRBC & July & $1.5 \times 10^{4} \pm 6 \times 10^{3}$ & $<1 \times 10^{2}$ & $2.2 \times 10^{4} \pm 7 \times 10^{3}$ & $4 \times 10^{4} \pm 3 \times 10^{3}$ & $4.1 \times 10^{4} \pm 4 \times 10^{3}$ \\
& August & $2.3 \times 10^{5} \pm 7 \times 10^{5}$ & $6 \times 10^{2} \pm 2 \times 10^{2}$ & $1.9 \times 10^{4} \pm 1.4 \times 10^{3}$ & $2.5 \times 10^{4} \pm 2.8 \times 10^{3}$ & $3.9 \times 10^{4} \pm 4.2 \times 10^{3}$ \\
& September & $2.9 \times 10^{5} \pm 9 \times 10^{3}$ & $3 \times 10^{2} \pm 1 \times 10^{2}$ & $1.4 \times 10^{5} \pm 5.6 \times 10^{4}$ & $2.6 \times 10^{4} \pm 2.8 \times 10^{4}$ & $2.3 \times 10^{5} \pm 2.8 \times 10^{4}$ \\
\hline \multirow{2}{*}{ DG18 } & May & $1.4 \times 10^{4} \pm 7 \times 10^{3}$ & $8.5 \times 10^{2} \pm 9 \times 10^{2}$ & $1 \times 10^{4} \pm 4 \times 10^{3}$ & $1.5 \times 10^{4} \pm 3 \times 10^{3}$ & $6.7 \times 10^{4} \pm 2.1 \times 10^{4}$ \\
& June & $8 \times 10^{4} \pm 1.3 \times 10^{4}$ & $<1 \times 10^{2}$ & $1.5 \times 10^{4} \pm 5 \times 10^{3}$ & $2 \times 10^{4} \pm 6 \times 10^{3}$ & $1.3 \times 10^{4} \pm 5.3 \times 10^{4}$ \\
& July & $1 \times 10^{4} \pm 9 \times 10^{3}$ & $5 \times 10^{2} \pm 1 \times 10^{2}$ & $1.7 \times 10^{4} \pm 6 \times 10^{3}$ & $2.5 \times 10^{4} \pm 8 \times 10^{3}$ & $5.4 \times 10^{4} \pm 4 \times 10^{3}$ \\
& August & $1.3 \times 10^{5} \pm 2.1 \times 10^{4}$ & $1 \times 10^{3} \pm 1 \times 10^{2}$ & $2 \times 10^{4} \pm 2.1 \times 10^{3}$ & $2.9 \times 10^{4} \pm 1.1 \times 10^{4}$ & $3.8 \times 10^{4} \pm 3.5 \times 10^{3}$ \\
& September & $1.5 \times 10^{5} \pm 2.5 \times 10^{4}$ & $9 \times 10^{2} \pm 2 \times 10^{2}$ & $5.9 \times 10^{5} \pm 4.9 \times 10^{3}$ & $3.1 \times 10^{4} \pm 1.1 \times 10^{4}$ & $3.9 \times 10^{5} \pm 7.8 \times 10^{4}$ \\
\hline
\end{tabular}

Detection limit: $1 \times 10^{2} \mathrm{CFU} \mathrm{g}^{-1}$. Maximum recommended level: $1 \times 10^{4} \mathrm{CFU} \mathrm{g}^{-1}[16]$.

DRBC: dichloran rose bengal chloranphenicol. DG18: dichloran glycerol 18\%.

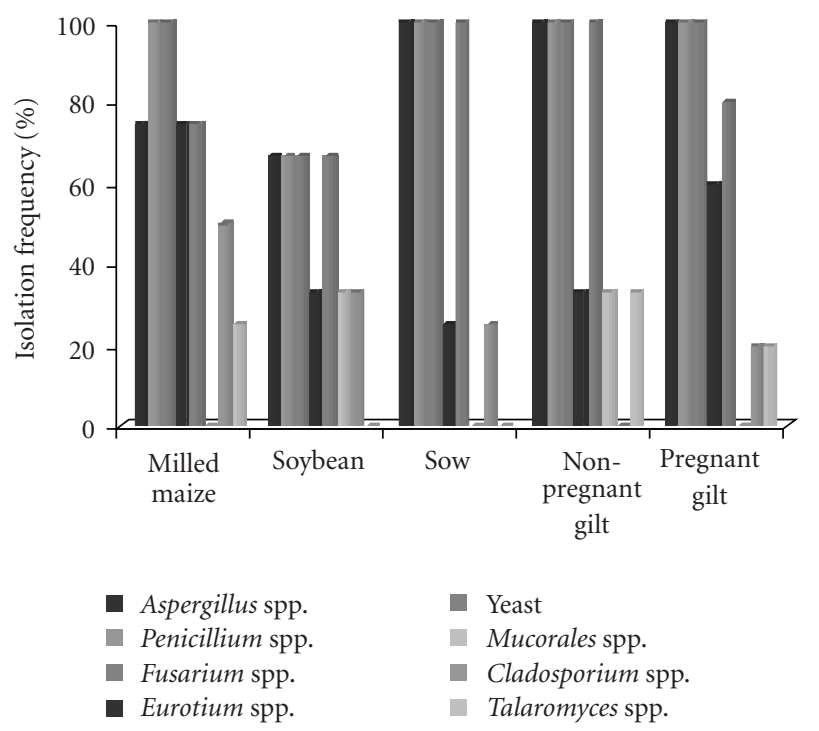

Figure 1: Isolation frequency of fungal genera (\%) from raw materials and finished feed for sows at different reproductive stages.

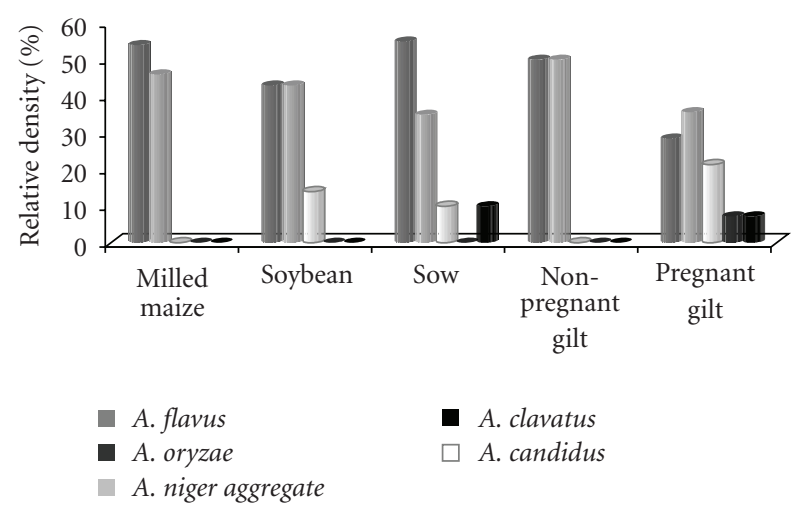

Figure 2: Relative density (\%) of Aspergillus spp. isolated from raw materials and finished feed for sows at different reproductive stages.

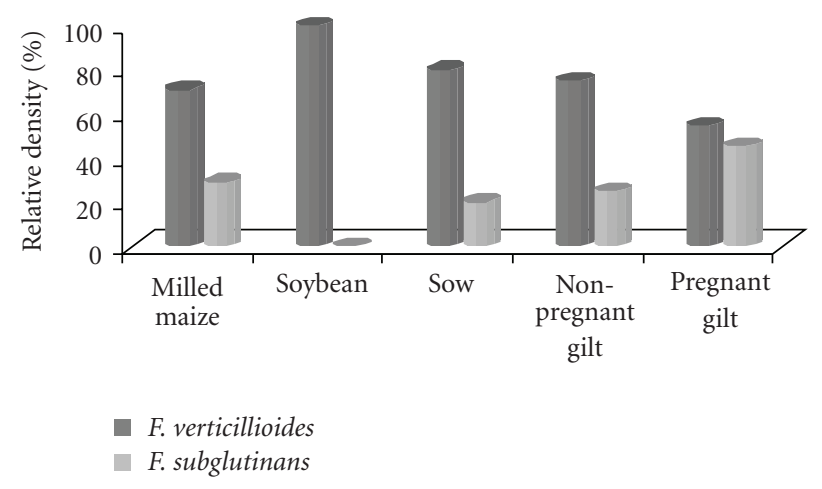

FIgURE 3: Relative density (\%) of Fusarium spp. isolated from raw materials and finished feed for sow at different reproductive stages.

Aspergillus oryzae and A. clavatus were not isolated from raw materials alone but were isolated from pregnant girl and sow feed at low frequency.

Two Fusarium spp. were identified. F. verticillioides was the predominant species in all analysed samples at levels that varied from $70 \%$ to $100 \%$ in raw materials and from $55 \%$ to $80 \%$ in finished feed. Fusarium subglutinans was only present in milled maize whereas this species was isolated from several kinds of finished samples at a relative density that varied from $20 \%$ to $45 \%$ (Figure 3 ).

Figure 4 shows the relative density of isolated Penicillium spp. from raw materials and finished feed. Eleven Penicillium spp. were isolated. In general, finished feed has higher Penicillium spp. diversity than that found in raw materials. Penicillium funiculosum was the prevalent isolated species, followed by $P$. purpurogenum and $P$. oxalicum in raw materials. In finished feed $P$. funiculosum, $P$. waksmanii, and $P$. crustosum were the prevalent isolated species.

Table 3 shows the $\mathrm{AFB}_{1}, \mathrm{ZEA}$, and $\mathrm{FB}_{1}$ OTA levels found in raw materials and finished feed. Raw material samples did not show OTA, $\mathrm{AFB}_{1}$, and ZEA natural contamination 
TABLe 3: Mycotoxin levels found in raw materials and finished sow feed at different reproductive stages.

\begin{tabular}{|c|c|c|c|c|c|c|}
\hline \multirow{2}{*}{ Mycotoxins } & & \multicolumn{2}{|c|}{ Raw material samples } & \multicolumn{3}{|c|}{ Finished pig feed samples } \\
\hline & & Milled maize & Soybean & Sow & Nonpregnant gilt & Pregnant gilt \\
\hline \multirow{3}{*}{$\mathrm{AFB}_{1}$} & Media $\pm \mathrm{SD}^{*}\left(\mu \mathrm{g} \mathrm{Kg}^{-1}\right)$ & $\mathrm{ND}^{\Psi}$ & ND & $228.2 \pm 95$ & ND & ND \\
\hline & Frequency $(\%)^{\dagger}$ & - & - & 80 & - & - \\
\hline & Samples over limits $(\%)^{\ddagger}$ & - & - & 100 & - & - \\
\hline \multirow{3}{*}{ OTA } & Media $\pm \mathrm{SD}\left(\mu \mathrm{g} \mathrm{Kg}^{-1}\right)$ & $\mathrm{ND}^{\Psi}$ & ND & ND & $0.259 \pm 0.123$ & ND \\
\hline & Frequency $(\%)$ & - & - & - & 100 & - \\
\hline & Samples over limits (\%) & - & - & - & 0 & - \\
\hline \multirow{3}{*}{$\mathrm{FB}_{1}$} & Media $\pm \mathrm{SD}\left(\mu \mathrm{g} \mathrm{Kg}^{-1}\right)$ & $660.9 \pm 415.7$ & $82.8 \pm 28.3$ & $334.2 \pm 178.4$ & $353.1 \pm 126.4$ & $341.6 \pm 118.2$ \\
\hline & Frequency $(\%)$ & 100 & 50 & 67 & 100 & 100 \\
\hline & Samples over limits (\%) & 0 & 0 & 0 & 0 & 0 \\
\hline \multirow{3}{*}{ ZEA } & Media $\pm \mathrm{SD}\left(\mu \mathrm{g} \mathrm{Kg}^{-1}\right)$ & ND & ND & $\mathrm{ND}$ & ND & ND \\
\hline & Frequency $(\%)$ & - & - & - & - & - \\
\hline & Samples over limits (\%) & - & - & - & - & - \\
\hline
\end{tabular}

* SD: standard deviation of three replicates. ${ }^{\dagger}$ Contamination frequency (\%): percentage of samples contaminated with mycotoxin. ${ }^{\ddagger}$ Percentage of samples contaminated with levels over the recommended: $\mathrm{AFB}_{1}: 20 \mu \mathrm{g} \mathrm{Kg}^{-1}$, OTA: $50 \mu \mathrm{g} \mathrm{Kg}^{-1}$, ZEA: $100 \mu \mathrm{g} \mathrm{Kg}{ }^{-1}$ (pregnant), FB 1 : $5000 \mu \mathrm{g} \mathrm{Kg}{ }^{-1}$. ${ }^{\Psi} \mathrm{Not}_{\mathrm{detected}}$

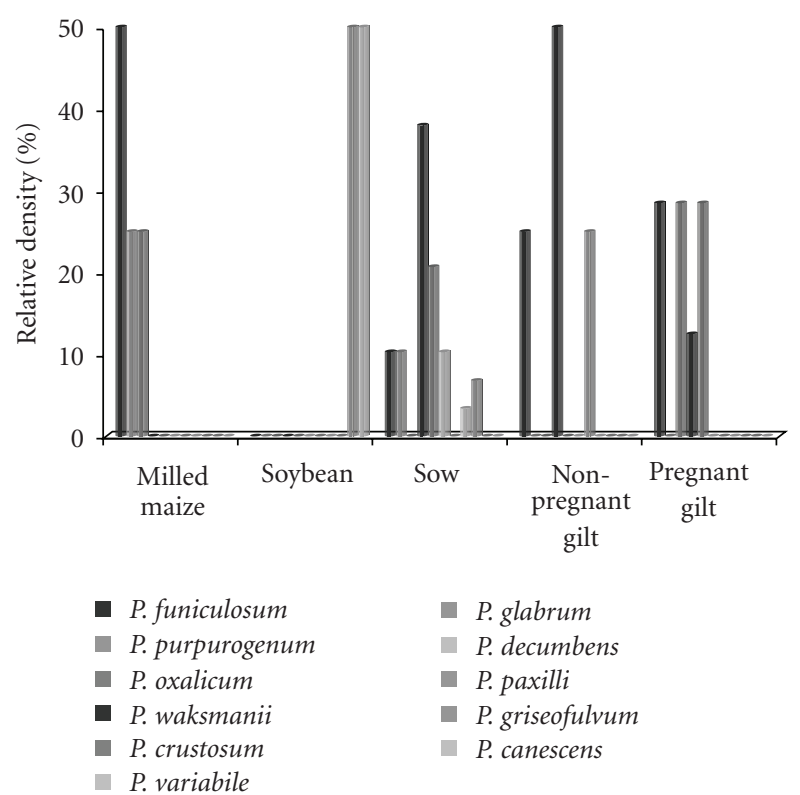

Figure 4: Relative density (\%) of Penicillium spp. Isolated from raw materials and finished feed for sow at different reproductive stages.

levels. Milled maize (100\%) and soybean samples (50\%) were contaminated with $\mathrm{FB}_{1}$ at levels that varied from 50.3 to $1137.64 \mu \mathrm{g} \mathrm{Kg}^{-1}$, respectively. None of the analyzed of raw material samples showed mycotoxin levels over the recommended limits for each studied mycotoxins $\left(0.02 \mu \mathrm{gg}^{-1}\right.$ for $\mathrm{AFB}_{1}, 250 \mu \mathrm{g} \mathrm{kg}^{-1}$ for OTA and $5000 \mu \mathrm{g} \mathrm{kg}^{-1}$ for FBs). Among finished feed samples, only feed intended for sows showed $\mathrm{AFB}_{1}$ natural contamination levels at high frequency $(80 \%)$. All Nonpregnant gilt samples were contaminated with low OTA levels whereas all of the other samples had not detected OTA levels or were below the quantification limit. All finished feed samples (100\%) were contaminated with similar $\mathrm{FB}_{1}$ levels that ranged from 99.8 to $512.4 \mu \mathrm{g} \mathrm{Kg}^{-1}$.

\section{Discussion}

Fungi and mycotoxins from raw materials and finished feed intended for sows at different reproductive stages were studied.

All analysed samples had counts over the proposed limits of $1 \times 10^{4} \mathrm{CFU} \mathrm{g}^{-1}$ [20]. This result suggests a high fungal activity that could affect the palatability and reduce the nutrient adsorption [21, 22] determining a low hygienic quality and an improper storage. These results are similar to those obtained by other researchers in pig feed in Argentina $[8,10]$. In this study, fungal species varied according to the analysed substrate. However, in general all samples showed that Aspergillus spp., Penicillium spp., and Fusarium spp., the main toxicogenic fungi, were the prevalent genera. Aspergillus flavus showed the highest relative density among Aspergillus spp. followed by A. niger aggregate spp. in raw materials. The same results were also found in finished feed. Several Brazilian authors obtained similar results to ours in maize and finished poultry and equine feed [2325]. They found A. flavus as prevalent species followed by $A$. candidus and $A$. niger aggregate spp. Other studies from Argentina found Aspergillus section Flavi species as prevalent followed by $A$. niger aggregate spp. from poultry and pig feed and frequencies were similar to those found in Brazil $[1,26]$. A high frequency of yeasts was also found. The significance of yeasts, which was frequently isolated, is not known. In this study, F. verticillioides was found as predominant followed by F. subglutinans. This prevalence has been informed from poultry feed in Latin America [2327]. However, Argentinean samples always showed higher F. verticillioides isolation frequency than Brazilian samples. Pereyra et al. [10] obtained results similar to ours from finished pig feed samples in central Argentina. However, they did not report the fungal contamination present in raw materials and finished feed intended for sows. Several isolated Penicillium such as $P$. oxalicum, $P$. raistrickii, 
P. paxilli, P. griseofulvum, and P. canescens are involved in food spoilage and produce different toxic fungal metabolites (secalonic acid, griseofulvin, verruculogen, cyclopiazonic acid, penitrem A) [12]. There is little information regarding the toxicological effects of these mycotoxins in animals [2]. Home-cereals used in farms for feed elaboration probably provided fungal field contamination.

The prevailing field environmental conditions should be influencing initial $\mathrm{FB}_{1}$ and ZEA production by potential producers, whereas the inadequate storage conditions should be influencing the $\mathrm{AFB}_{1}$ and OTA production by potential producers, which were present in finished feed. Our previous studies carried out with $\mathrm{FB}_{1}$ and OTA feedstuff contamination demonstrated the absence of this toxin in raw materials but levels were detected in stored feed $[8,10]$.

It is important to state that the presence of fungi in feed does not automatically indicate the mycotoxin presence. In this work, the presence of $F$. verticillioides was related to the $\mathrm{FB}_{1}$ contamination. However, this behaviour was not shown by A. flavus, A. niger aggregate spp., Fusarium spp., and the presence of their mycotoxins in samples (AFs, OTA, and ZEA, resp.). Similar results were found in samples intended for pigs at different growth stages in central Argentina [10].

The present study has shown the simultaneous occurrence of carcinogenic mycotoxins. The cooccurrence of these toxins in pig feed was demonstrated in the central area of our country $[8,10]$. However, none of these studies demonstrated the presence of fungi and mycotoxins in feed intended to pigs at reproductive stages. In animal production, the simultaneous occurrence of mycotoxins brings not only bad health in animals but also low production. Various mycotoxins may occur simultaneously depending on the environmental and substrate conditions [2]. Considering this coincident production, humans and animals may be exposed to mixtures rather than individual compounds.

Regulations on standard products in the animal feed sector established that the current maximum permitted level for $\mathrm{AFB}_{1}$ for pigs is $0.02 \mu \mathrm{gg}^{-1}$ [24]. Aflatoxin $\mathrm{B}_{1}$ levels were higher than the recommended limits in $100 \%$ finished samples intended for sows. The European Union (EU) released guidance for OTA, FBs, and ZEA levels in animal feed (http://ec.europa.eu/information_society/activities /digital_libraries/doc/recommendation/recommendation/en .pdf) that establish allowed limits of $250 \mu \mathrm{g} \mathrm{kg}^{-1}$ for OTA and $5000 \mu \mathrm{g} \mathrm{kg}^{-1}$ for FBs. In our study, samples did not yield FBs and OTA levels higher than these allowed limits.

The presence of mycotoxins indicates the existence of contamination. Since raw materials are a primary source of the moisture and fungi found in feed, the first important step in controlling moisture in feed is to control it in the raw materials from which the feed is prepared. Since all feed ingredients contain moisture, they should be monitored and their moisture content should be controlled in order to prevent the occurrence of mycotoxicoses in animal production, to reduce economic losses and to minimize hazards to human health.

This is the first study supplying data on fungi and the occurrence of mycotoxins in sow feed at different reproductive stages.

\section{Acknowledgments}

This work was carried out with grants from SECYT-UNRC, CONICET, PICT, PICT-CNPq, and FONCYT-PICTO. The authors thank Mr. Jorge Liaudat for his assistance in getting the sow feed samples.

\section{References}

[1] J. Chelkowski, "Mycological quality of mixed feeds and ingredients," in Cereal Grain, Mycotoxins, Fungi and Quality in Drying and Storage, J. Chelkowski, Ed., pp. 217-227, Elsevier, Amsterdam, The Netherlands, 1991.

[2] CAST (Council for Agricultural Science and Technology), "Mycotoxins: risks in plant, animal and human systems," Tech. Rep. 139, Task Force, Ames, Iowa, USA, 2003.

[3] H. P. Van Egmond and G. J. A. Speijers, "Survey of data on the incidence and levels of ochratoxin A in food and animal feed worldwide," Journal of Natural Toxins, vol. 3, pp. 125-144, 1994.

[4] M. L. Abarca, F. Accensi, M. R. Bragulat, and F. J. Cabañes, "Current importance of ochratoxin A-producing Aspergillus spp," Journal of Food Protection, vol. 64, no. 6, pp. 903-906, 2001.

[5] C. Magnoli, A. Astoreca, L. Ponsone, M. G. FernándezJuri, S. Chiacchiera, and A. Dalcero, "Ochratoxin A and the occurrence of ochratoxin A- producing black aspergilli in stored peanut seeds from Córdoba, Argentina," Journal of the Science of Food and Agriculture, vol. 86, no. 14, pp. 2369-2373, 2006.

[6] World Health Organization (WHO), Evaluation of Certain Mycotoxins in Food, vol. 906 of WHO Technical Report Series, World Health Organization, Geneva, Switzerland, 2002.

[7] L. R. Harrison, B. M. Colvin, J. T. Greene, L. E. Newman, and J. R. Cole Jr., "Pulmonary edema and hydrothorax in swine produced by fumonisin B1, a toxic metabolite of Fusarium moniliforme," Journal of Veterinary Diagnostic Investigation, vol. 2, no. 3, pp. 217-221, 1990.

[8] C. Magnoli, S. M. Chiacchiera, R. Miazzo, et al., "The mycoflora and toxicity of feedstuffs from a production plant in Cordoba, Argentina," Mycotoxin Research, vol. 18, pp. 7-22, 2002.

[9] C. A. R. Rosa, K. M. Keller, L. A. M. Keller, et al., "Mycological survey and ochratoxin A natural contamination of swine feedstuffs in Rio de Janeiro State, Brazil," Toxicon, vol. 53, no. 2, pp. 283-288, 2009.

[10] M. L. González Pereyra, C. M. Pereyra, M. L. Ramirez, C. A. R. Rosa, A. M. Dalcero, and L. R. Cavaglieri, "Determination of mycobiota and mycotoxins in pig feed in central Argentina," Letters in Applied Microbiology, vol. 46, no. 5, pp. 555-561, 2008.

[11] A. Yiannikouris and J.-P. Jouany, "Mycotoxins in feeds and their fate in animals: a review," Animal Research, vol. 51, no. 2, pp. 81-99, 2002.

[12] J. I. Pitt and A. D. Hocking, Eds., Fungi and Food Spoilage, Blackie Academic Press, London, UK, 2nd edition, 1997.

[13] M. A. Klich, Identification of Common Aspergillus species, CBS, Utrecht, The Netherlands, 2002.

[14] P. E. Nelson, T. A. Toussoun, and W. F. O. Marasas, Eds., Fusarium Species: An Illustrated Manual for Identification, The Pennsylvania State University Press, University Park, Pa, USA, 1983. 
[15] M. W. Trucksess, M. E. Stack, S. Nesheim, R. H. Albert, and T. R. Romer, "Multifunctional column coupled with liquid chromatography for determination of aflatoxins B1, B2, G1, and G2 in corn, almonds, brazil nuts, peanuts, and pistachio nuts: collaborative study," Journal of AOAC International, vol. 77, no. 6, pp. 1512-1521, 1994.

[16] K. A. Scudamore and S. J. MacDonald, "A collaborative study of an HPLC method for determination of ochratoxin A in wheat using immunoaffinity column clean-up," Food Additives and Contaminants, vol. 15, no. 4, pp. 401-410, 1998.

[17] G. S. Shephard, E. W. Sydenham, P. G. Thiel, and W. A. Gelderblom, "Quantitative determination of fumonisins B and B by high-performance liquid chromatography with fluorescence detection," Journal of Liquid Chromatography, vol. 13, no. 10, pp. 2077-2087, 1990.

[18] M. B. Doko, S. Rapior, A. Visconti, and J. E. Schjoth, "Incidence and levels of fumonisin contamination in maize genotypes grown in Europe and Africa," Journal of Agricultural and Food Chemistry, vol. 43, no. 2, pp. 429-434, 1995.

[19] AOAC, Official Methods of Analysis, sec. 972-26, 976-22, Association of Official Analytical Chemists, Gaithersburg, Md, USA, 1995.

[20] Good Manufacturing Practices (GMP), GMP Certification Scheme Animal Feed. Sector 2006, Appendix 1: Product standards; Regulations on Product Standards in the Animal Feed sector, GMP14, 2008.

[21] H. M. Martins and M. L. Martins, "Mycological quality evaluation of bovine feedstuffs (Portugal: 1996-1999)," Revista Portuguesa de Ciencias Veterinarias, vol. 96, pp. 85-88, 2001.

[22] V. W. Ogundero, "Toxigenic fungi and the deterioration of Nigerian poultry feeds," Mycopathologia, vol. 100, no. 2, pp. 75-83, 1987.

[23] M. E. Fraga, F. Curvello, M. J. Gatti, L. R. Cavaglieri, A. M. Dalcero, and C. A. da Rocha Rosa, "Potential aflatoxin and ochratoxin a production by Aspergillus species in poultry feed processing," Veterinary Research Communications, vol. 31, no. 3, pp. 343-353, 2007.

[24] K. M. Keller, B. D. Queiroz, L. A. M. Keller, et al., "The mycobiota and toxicity of equine feeds," Veterinary Research Communications, vol. 31, no. 8, pp. 1037-1045, 2007.

[25] G. R. Oliveira, J. M. Ribeiro, M. E. Fraga, et al., "Mycobiota in poultry feeds and natural occurrence of aflatoxins, fumonisins and zearalenone in the Rio de Janeiro State, Brazil," Mycopathologia, vol. 162, no. 5, pp. 355-362, 2006.

[26] C. Magnoli, A. M. Dalcero, S. M. Chiacchiera, R. Miazzo, and M. A. Saenz, "Enumeration and identification of Aspergillus group and Penicillium species in poultry feeds from Argentina," Mycopathologia, vol. 142, no. 1, pp. 27-32, 1998.

[27] A. Dalcero, C. Magnoli, M. Luna, et al., "Mycoflora and naturally occurring mycotoxins in poultry feeds in Argentina," Mycopathologia, vol. 141, no. 1, pp. 37-43, 1998. 

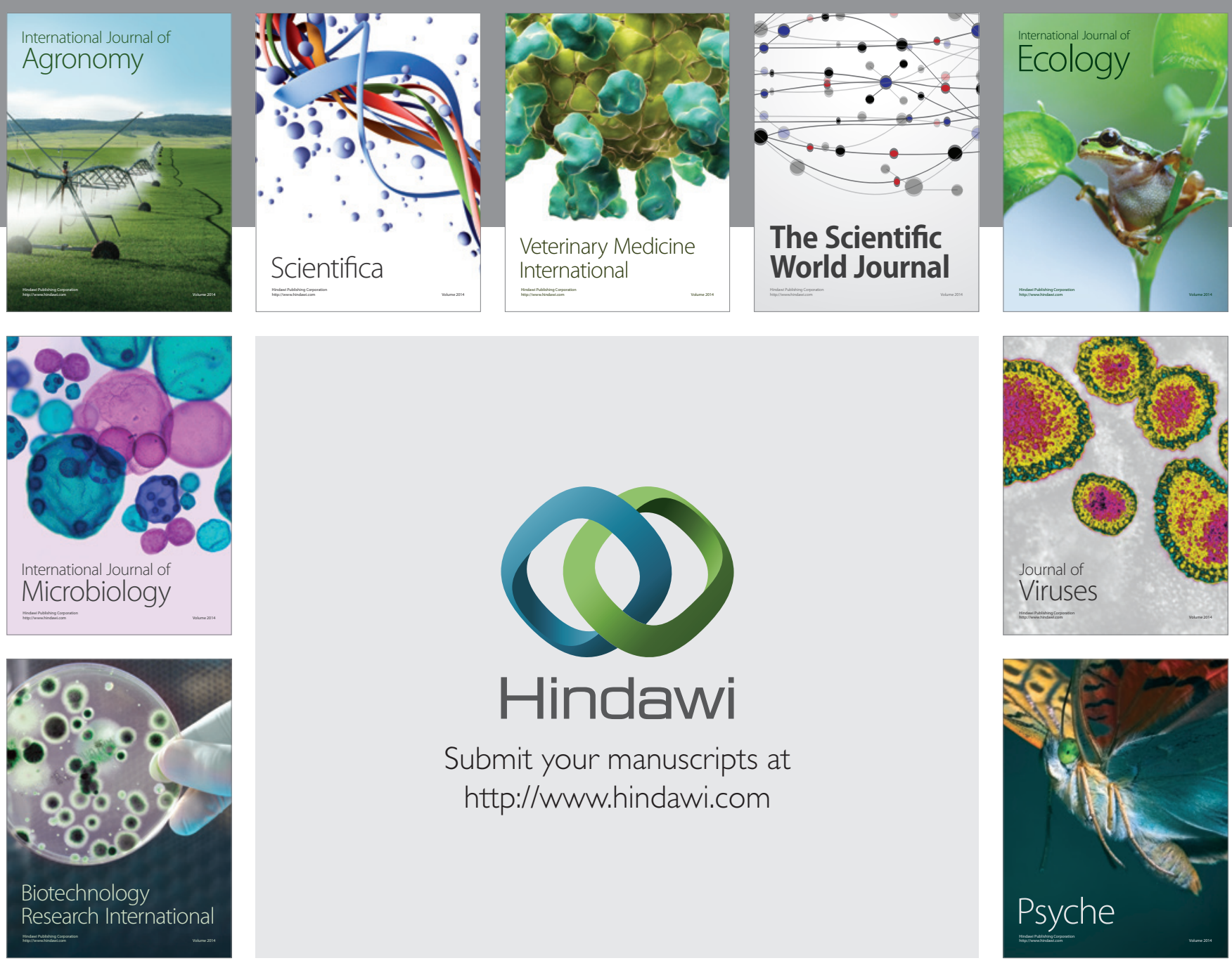

Submit your manuscripts at

http://www.hindawi.com
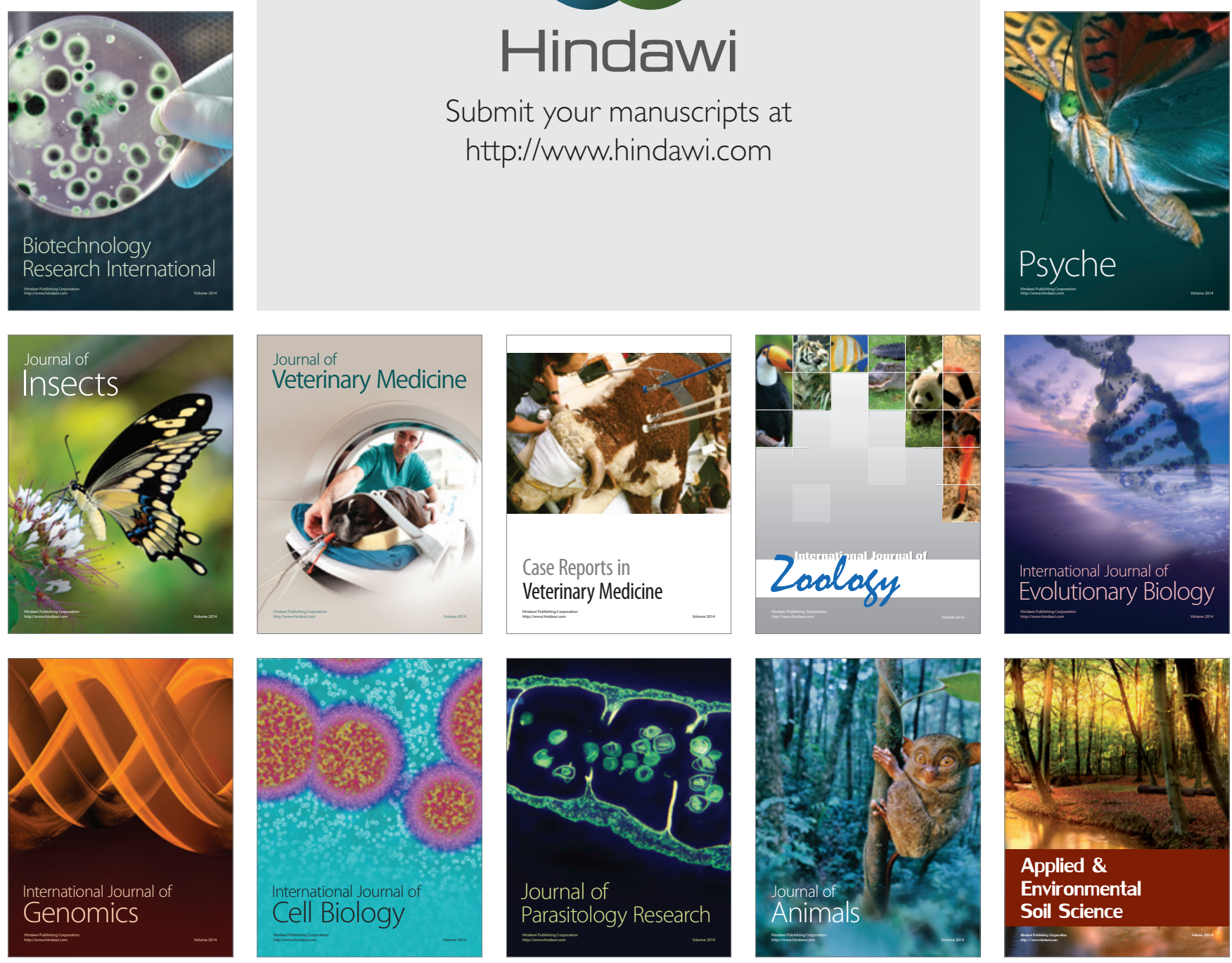